\title{
On the Existential Situation of a Person with Dementia: The Drama of Mankind Is Repeated in the Drama of Dementia
}

\author{
Björn Freter \\ Independent Scholar, Dürerstrasse 43A (Gartenhaus), Berlin 12203, Germany
}

\begin{abstract}
Man suffers from a very particular fate, namely that of being besieged by questions which he cannot answer and cannot ignore either. The ability to pose questions like these is a key characteristic of the fundamental existential situation of mankind. Every person must find his or her own particular method of coping with such questions. This makes up a significant part of the human maturing process. People with dementia, having already found their personal solution to cope with the problem of these unanswerable questions, radically stumble into this existential situation once again. The problem of this repetition is that the people with dementia can only make limited use, if indeed any use at all, of their previously successful biographical strategies. The drama of human existence as such thus repeats itself within a person with dementia. We must recognise the seriousness of this task. We thus must support people with dementia in coping existentially with this renewed task in the best possible way. The existential dignity of this task is no different from that of a young person. This insight is very important for the care of patients: People with dementia should be recognised as people in an existential situation.
\end{abstract}

Key words: Dementia, facticity, existentiality, drama, trauma, contingency, decontingentisation, Immanuel Kant.

\section{Introduction}

We intend to show that it is important to understand people with dementia not only as sufferers of a neuro-degenerative disease, but as people who find themselves, albeit due to the disease, in a deep existential crisis.

In order to grasp this crisis adequately, we require an appropriate anthropology.

As far as we can see, such an anthropology is a sensitive desideratum in the lively ongoing discussion about dementia, or it should at least be recognised as such. For we do indeed find several basic attempts at an anthropological approach, for example in the works of Tom Kitwood [1] and Naomi Feil [2]. With these authors in particular, however, we find the problem of a normatively very demanding anthropology which

Corresponding author: Björn Freter, Ph.D., research fields: philosophy of dementia, philosophy of medicine, philosophy of nursing, philosophy of normativity, ethics, literary studies. E-mail: freterb@freenet.de. fails to observe-people both with and without dementia-instead approaching the issue in terms of a normative programme that often distorts the view of the phenomena purportedly under investigation. This is particularly evident in the large number of unprovable claims about the inner state of people with dementia. Naomi Feil, for example, claims consistently that in the case of dementia, we find someone who is-willingly_returning to his or her past to resolve unfinished psychological issues. This, Feil states, is evidence of the wisdom of the elderly. These assertions are virtually impossible to prove, and yet they are the basis of her entire anthropological programme. We consider such assertions to be quite dangerous. They can (paradoxically, because it is precisely what Feil attempts to counteract when she constantly points out the importance of the emotional life of people with dementia) lead us to over-rationalise people with dementia: People with dementia do what they do because they have a 
purpose. This seems to us to be completely inappropriate. As we intend to show, this idea displays a wanton disregard for the existential crisis of people with dementia — a crisis which arises from perplexity and certainly not, as we suspect, from planned confrontation with oneself.

There is no need, as Feil does, to read wisdom into dementia in order to preserve the dignity of people who have it. People with dementia are humans. They have what it takes to firmly defend their human dignity. To talk about some kind of secret wisdom is not a caring devotion to people with dementia, but rather a protection of the observer who is unable to endure the mystery of the condition.

It is clear to us that these anthropologies are virtually unheeded in day-to-day clinical practice. Particularly in the case of Feil's validation approach, which continues to be widely applied, there is often a strict separation between the-doubtlessly successful and very effective - practical instructions and the theoretical basis of validation; the latter, as is our impression, is for the most part completely ignored.

We suspect, however, that the anthropology of dementia, or at least a preliminary approach towards a phenomenology of dementia, is actually of considerable importance, with this contribution thus constituting an initial attempt at this task. We hope that with the help of such a phenomenology, it may be possible on the one hand to enable medical personnel, particularly in non-specialised acute care hospitals, to gain improved access to people with dementia, while on the other hand also making the behaviour of people with dementia more comprehensible to wider sections of the population. Such an understanding is surely the most important prerequisite for a successful integration of people with dementia into society.

\section{Methods}

In the course of this contribution, we will make extensive use of philosophical analysis. It is therefore not an empirical study in the narrow sense, even though we make considerable effort to arrive at a phenomenally appropriate grasp of dementia and to maintain compatibility with the insights of medical research, inasmuch as they are known to us. We limit ourselves in the description of dementia to the cortical forms of the condition, particular those of the Alzheimer type.

\section{Philosophical Discussion}

\subsection{A Particular Fate}

Man, as we can still ascertain with the aid of Kant's insights, suffers from a very particular fate, namely that of being besieged by questions which he cannot answer, such as those relating to life after death, the existence of God etc. These questions cannot be answered, since they necessarily exceed the limits of human understanding. But we are not able to ignore them either, since they arise from "the very nature of reason itself” [3], as Kant puts it in the Critique of Pure Reason.

Prior to Kant, philosophy had understood these questions as ones to be answered by a theory of reality, whatever form that theory may take-an idea that persists in some circles today.

These theories of reality, as we must bemoan in accordance with Kant, have always arisen from principles confirmed by experience. Ultimately, however, "because the questions never cease" [4], reason-with Kant in this context always thereby referring to man-is ensnared by principles "which exceed every possible experimental application” [4]. It is with these principles that man attempts to grasp the world. However, he often loses sight of the fact that in the course of his investigations, because he has drawn his principles entirely from reason and not from experience, it is no longer the world, but rather man himself that has become the object of investigation.

We simply do not experience that which must be experienced in order to answer our questions about reality-if such experiences can indeed be had at all 
by any creature. Our possibilities for experience end long before our need to question is exhausted.

\subsection{Beyond Experience}

When we deal with something beyond the possibilities of our experience, we deal not with an external reality, but first and foremost only with ourselves, our capability to manage reality, our own capacity for reason.

In the dealings with this pure capacity for reason, we recognise only the laws of this capacity itself. In pure reason, we recognise ourselvess, and, as significant as this realisation may be, we can never recognise in it the world and its laws as such. We recognise here rather our own laws of reason, and inasmuch as these laws transcendentally preform reality, we recognise, so to speak, the forms that reality must always take for us.

Philosophy, or indeed metaphysics, had, until the critical change of direction provided by Kant, thus considered the study of the nature of reason to be a study of the nature of reality.

We wish to leave this strange disconnectedness of man from his reality, this strange unbridgeable distance between man and his environment that lies within this supposition and against which Heidegger so indignantly protested, by the wayside for the moment and first follow Kant a little further.

\subsection{Our Practial Interest}

Kant namely points out another misunderstanding: It is not in fact the theoretical interest of reason that makes these unanswerable questions so pressing for us. It is not of acute necessity for us to know the essential nature of God, but rather to know what He means for us in a practical sense. We want to know-indeed we must know-what is to be done if God exists, or, to proceed from Kant to Nietzsche, what is to be done if no god exists-practical primacy is once again valid here.

The fact that our reason surges towards the unanswerable questions may well be taken as evidence of man's theoretical interest, his theoretical curiosity. But above all else, this is a testament to the fundamental practical interest of man which precedes all other concerns, our existential, our practical requirements: the deepest urge of our reason, the deepest urge of mankind concerns not the question "what is the case?", but rather the question "what ought I to do?”.

We are, as we can learn from Kant, naturally drawn to something which we, just as naturally, do not have the capacity - at least not theoretically—to understand. We do not experience that which must necessarily be experienced in order to do so. And even if we were to experience this, we would not be in a position to process these experiences. They would remain a puzzle to us. We would certainly then find ourselves faced with another, a new puzzle, but nevertheless a puzzle.

\subsection{The Human Drama}

We suspect, thus definitively moving away from Kant (after a thoroughly free interpretation in the first place), that the practical necessity of man that perpetually manifests itself anew in the question "what ought I to do?" can never ultimately find peace. Man is born into eternal unrest.

This unrest is not to be discredited as a deficiency, but is rather to be accepted as humanity.

No matter how often we may have answered the question of what is to be done, we encounter it again and again. In this question, the incompleteness of our human vitality is demonstrated in undisguised form. Human life is always incomplete because we perpetually encounter the question of what is to be done, and because it is virtually impossible to ignore it-always the same yet different every time. Indeed, we do not actually wish to ignore it.

For it is from the practical answers to this perpetually new yet eternally identical question, i.e. from that which we do once we have found 
out-however this may happen-what is to be done, that we determine and grasp who we are. It is here, in an emphatic sense, that we begin to exist as ourselves. It is here that our story is created.

This interminable task of self-appropriation, this interminable work on our practical self-determination and the unavoidable risk of failing in this regard makes our life a dramatic affair.

How do we deal with this human drama? How do we manage our incompleteness? How do we actually cope with our very particular fate?

\subsection{Facticity}

To describe the way, we [5] handle our situation, we wish to introduce the concepts of facticity and existentiality (Fig. 1).

The term facticity refers not to objective reality, reality as it truly is - whatever that may be, but rather to that which we perceive as reality, that which we assume, either tacitly or expressly, subconsciously or consciously, to be given, that which we consider to be something that is as it is.

Facticity is thus not only an ontological term applying to that which is, but at the same time a hermeneutic term applying to the interpretation of being.

With the term facticity, we describe reality as an interpretation, as something that we consider to be reality. In every reference to reality we find someone who considers something to be real-this is the hermeneutic element of facticity-and something that is referred to as real, as reality-this is the ontological element of facticity.

The intention here is not to engage in an epistemological analysis, but rather to understand what is considered to be reality in order to then understand what is considered possible. For considering something possible means, as we will now clarify, considering it to be the object of existential practice, the object of normative practice.

\subsection{Existentiality}

Existentiality, or, as we can also say, existential practice, means realisation, means the creation of existential facts.

While we understand facticity as referring to reality and the assumption of reality, existentiality refers to the positing of reality. Within the framework of facticity, we are able to augment reality with existential facts (Fig. 1).

The creation of existentiality as quasi-facticity means the extension of the subject area of reality and at the same time a narrowing of the existential range as initially set by facticity (Fig. 2).

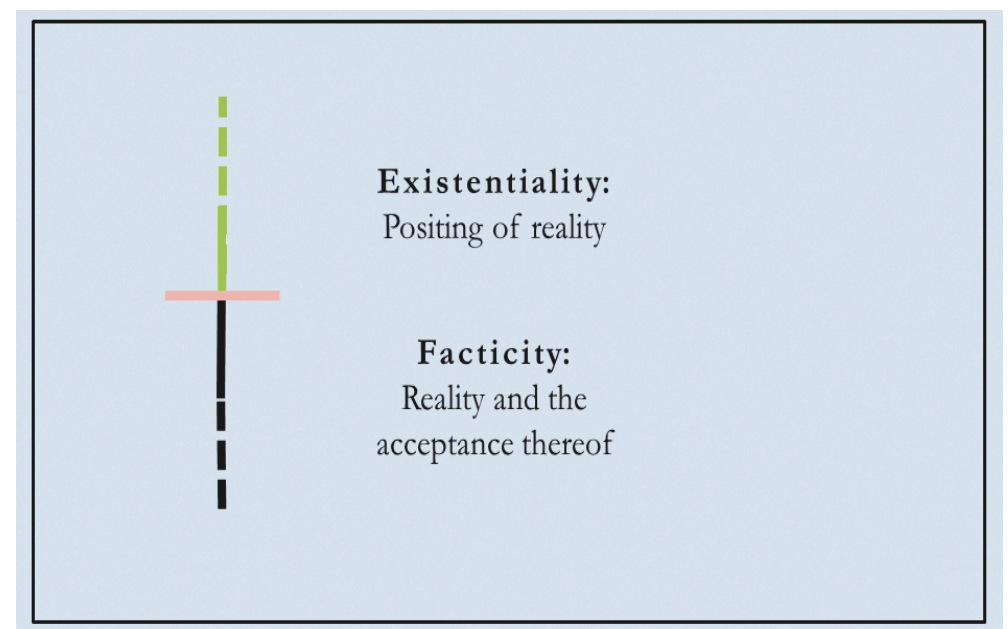

Fig. 1 Facticity and Existentiality. 


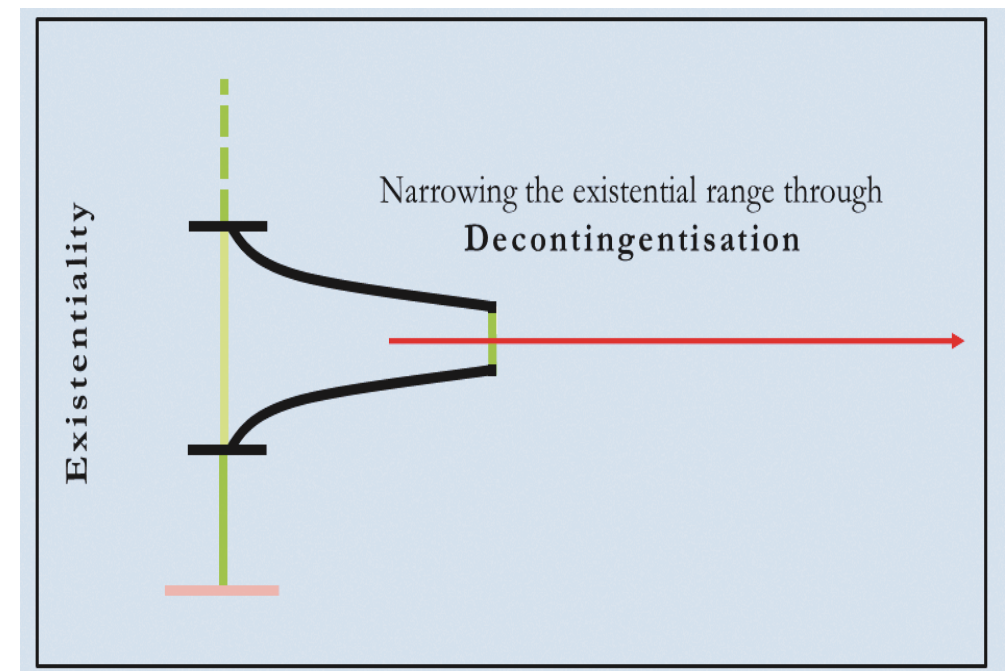

Fig. 2 Decontingentisation narrows the existential range.

We now wish to take a closer look at a specific pattern that occurs, as far as we can see, in all existential practices: decontingentisation.

\subsection{Decontingentisation}

We decontingentise, for example, when we, to name two very prominent examples of existential practice, care or love [6, 7].

The beloved person, whose story, for whatever reason and in whatever way, comes into contact with our own story (in the literal sense of contingere), becomes someone with whom we normatively connect ourselves. His or her well-being is for us no longer something that merely is, something that may or may not be present, but instead becomes something that ought to exist, it becomes for us an ought-to-be. To be more precise: We posit his or her well-being as something that ought to be. We create an existential fact. We thus draw the beloved person out of the approximate, out of the somehow, out of the this-way-or-that, out of contingency (Fig. 2).

The loving person works actively against contingency. In the course of loving, we wrest one certain course of events away from contingency. To love thus necessarily means to decontingentise. In love, not everything should be possible, but rather only that which is in accordance with the love.

\subsection{Our Self-Understanding}

Through the decontingentisation, through the positing of an ought-to-be, our hermeneutics of reality, our entire understanding of reality, prove to be normative.

We certainly organise reality according to what we recognise, what we perceive, what we are able to think etc.-but also according to that on which we can set our heart.

Our existentiality, our existential practice, is of central importance for our self-understanding: whom we see ourselves as depends largely on which existential facts we posit, which 'is' we recognise as an ought-to-be, which ought we dedicate ourselves to.

When we love another person, to return to our example, we are fundamentally determined by our function as one who loves, we are fundamentally determined by our function as being the one who has dedicated him or herself unconditionally to the ought-to-be of the well-being of the beloved person.

Because it is a matter here of the realisation of that which is possible, our self-understanding fundamentally depends on what we consider to be real. Our self-understanding thus fundamentally depends on the facticity that precedes our existentiality.

The wide variety of human biographical concepts is determined by the many ways in which facticity and 
existentiality can be related. Facticity and existentiality exist not in static, but rather in dynamic proportion to one another.

Our biographical concepts differ primarily in terms of what we consider to be real and what we consider to be possible-and, to complete the thought, in terms of what they raise out of the realms of possibility not only into being, but also to become an ought-to-be.

\subsection{Contingentisation Trauma}

Of course, we are permanently threatened by a potential erosion of the positing of the ought-to-be, of decontingentisation, by the potential for the impossible to once again become possible, by the potential to be pushed back into contingency, by the potential to become traumatised.

Being traumatised, in our terminology, means to experience an event that forcefully pushes us into a world in which more is possible than we had hoped, means to experience contingentisation (Fig. 3).

In the course of trauma, the incompleteness returns to our lives in a quasi uncontrolled manner, sometimes suddenly, sometimes stretched out over a longer period of time. There are once again many possibilities to be lived out, since that which we had previously existentially determined has now crumbled.
The question of what is to be done is now posed anew, although we believed this conundrum to have been overcome.

If the possibility of existential normative connection is taken from us, we lose not only that to which we had formed a connection, but also the determination of ourselves through the other person that reflects back upon us through this connection. We are then once again, or at least more than before, left to our own devices. We find ourselves in a state of existential under-determination.

A life that experiences no trauma is virtually impossible to imagine. Everyone, sooner or later, will experience trauma, in most cases several times.

But we possess the ability, mostly without any professional help, to detraumatise, even though this is usually tremendously strenuous. We must bring ourselves to repeat that which we have already done before. We have to re-organise and re-establish our existential practice of decontingentisation: We have to narrow the existential range again (Fig. 4).

Left to our own devices, we must once again existentially narrow contingency and must search anew amidst the oversupply of possibilities for something with which we can connect ourselves: We must repeat the process of self-determination.

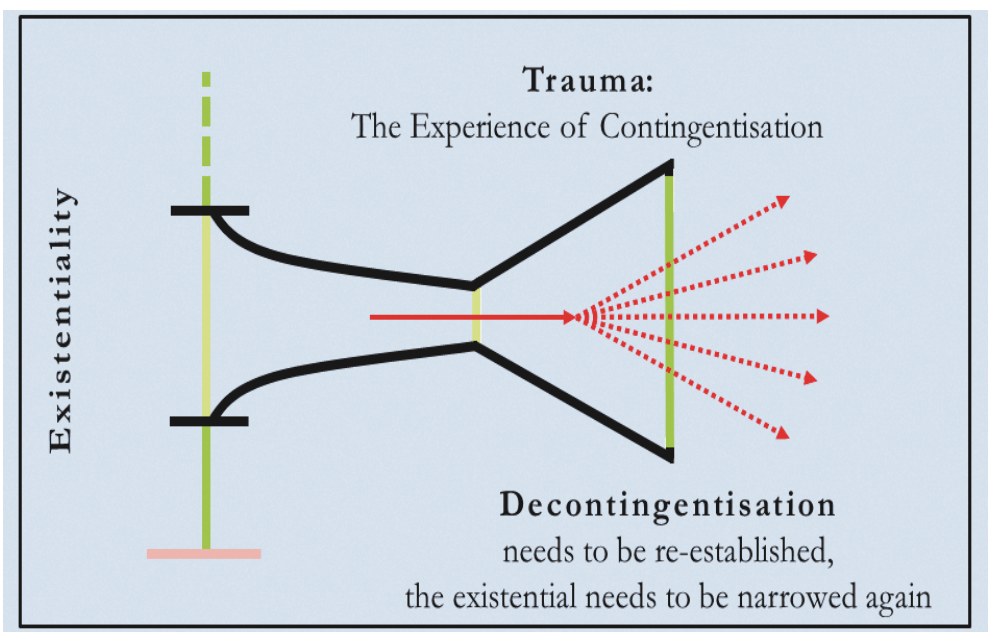

Fig. 3 Trauma as a push back into contingency. 


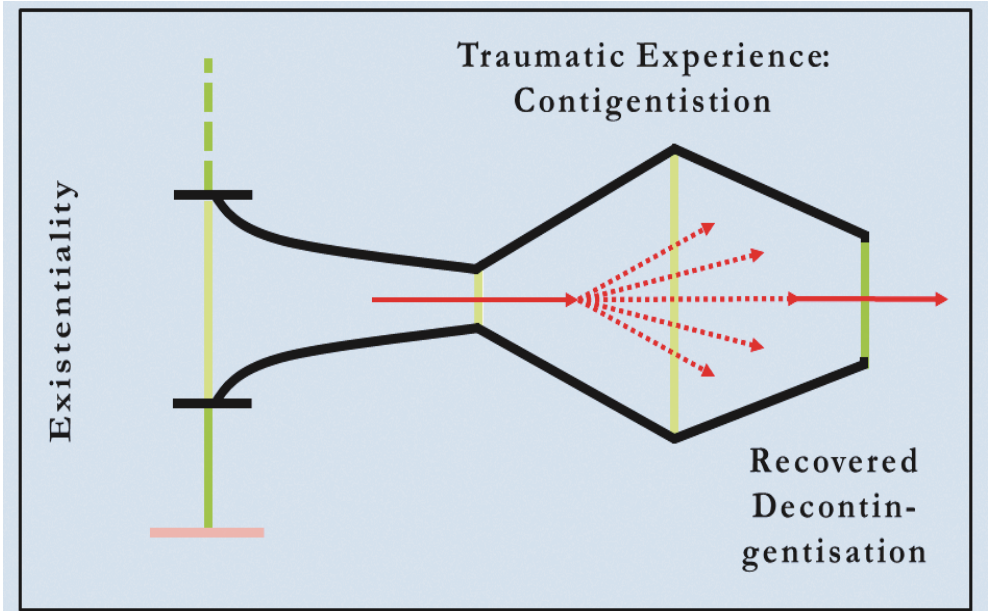

Fig. 4 Recovering Decontingentisation.

\subsection{Dealing with the Human Drama}

We have been able to gain an impression of how we manage the human drama: through existential practice, the positing of existential facts, decontingentisation.

Our existential practice depends, on the one hand, on the facticity that precedes the existentiality remaining relatively stable, and on the other hand, on the relationship between, as we shall call them, the transcendental existence forms facticity and existentiality also remaining relatively stable.

The existence forms, as we have already mentioned, certainly exist in dynamic proportion to one another. But even when, as may well be the case in the course of a lifetime, the dynamic of this relationship truly becomes evident and our existentiality is disrupted through a trauma or our facticity - and with it the existentiality—shifts, for example through a spiritual experience, the exceptional nature of these events does not - in the majority of cases-destroy our ability to find orientation in that which we consider to be possible and in that which we consider to be real.

What happens, however, when a relative stability of facticity can no longer be maintained? What happens when the proportions of facticity and existentiality lose their relative stability?

\subsection{The Human Drama, Again}

Facticity, as we have said, precedes existentiality.
Within the framework of facticity, we engage in existential practice: The spectrum of our possibilities, our existentiality, is confined to the borders of that which we consider to be reality-however we may reach this conclusion. That which we consider to be real is thus of immense importance for our existentiality.

Through our existential practice-or at least including it - we in turn determine who we are. This, it seems, is especially important when we normatively connect ourselves with another, be it a person, an idea, a country, or anything else.

We would now like to examine a specific case in order to discuss what happens when a dementia disease alters this existential practice [8]:

An approximately 80-year-old man, a professor emeritus of medicine, was admitted to hospital by his relatives due to spurious actions in his domestic environment. Following extensive diagnostic investigation (anamnesis, third party anamnesis, neuro-psychological examination, cranial MRT, EEG, comprehensive laboratory and liquor diagnostics), a cortical dementia, probably of the Alzheimer type, was diagnosed. In the course of his time in hospital, the patient was increasingly disorientated and confused. While the patient initially wished to accompany the doctors on a round of the ward during the first few days, he became very agitated one evening after about a week spent in the hospital and began to demand to 
be allowed to call his wife. He claimed to be very worried about her and feared that something had happened to her. The wife of the patient had in fact committed suicide five years previously, about which nothing further was known. Attempts to distract the patient from his intentions were to no avail. The patient thus eventually had to be confronted with the death of his wife. Upon hearing this news, he collapsed, silent and shocked. After a few minutes, however, he once again demanded an opportunity to call his wife. This cycle was repeated a number of times over the course of several hours. The patient was constantly accompanied by a doctor or caregiver (nurses and night shift personnel). He attempted several times to leave the hospital in order to, as he put it, "see to things at home". The cycle could only be broken once the patient's son was contacted via telephone and was able to calm his father. The son also consented to a one-off sedative dose of medication with a benzodiazepine. The patient was then able to sleep for several hours. In the following days, several more episodes of worry about his wife occurred. These were always combined with the urgent wish to contact her. During this time, however, he seemed to be more easily distracted. The patient was eventually discharged and placed in the care of a nursing service.

Our patient, let us call him Mr M., experiences his own reality as foreign. $\mathrm{He}$ is disorientated and confused, i.e. he can no longer interpret reality in such a way that he can orientate himself within it. The hermeneutic element of his facticity is changing. $\mathrm{Mr}$ M. is certainly still working on his reality, he still holds a hermeneutic interest, but this work no longer leads to an orientation, it no longer leads to a reduction in the confusion of all that which surrounds him, it no longer leads to a-at least relatively - unified stream of life. Reality no longer appears to Mr M. as implicitly interpretable, as it had done previously, but rather as seemly unhewn and crude. Mr M. has fallen into a kind of non-implicitness [9]. This may happen to us all for a short period of time, but for Mr M., this experience persists. Reality has become a perpetual puzzle. Since he clearly remembers, as is typical for this middle to advanced stage of Alzheimer dementia, that this has not always been the case, we must assume that our patient finds himself in a highly stressful state. Or to put it more sharply: the persisting inability to interpret reality results in an existential crisis that reaches into the farthest depths of a person. It is therefore not surprising that we find so many cases of depression and anxiety disorders among people with Alzheimer dementia [10].

It seems that in the dialectic of ontology and hermeneutics, the ontological element of Mr M.'s facticity is gaining the upper hand. $\mathrm{Mr} \mathrm{M}$. is not confused by the question of reality as such-he is not surprised that something exists rather than nothing. The problem is rather that his hermeneutic powers have changed so much that they can no longer grasp reality in the accustomed manner. Whatever his reality hermeneutics produce, the familiar and hence expected interpretation of reality can no longer be achieved.

Mr M. thus does not live in a state of primarily ontological confusion, but rather primarily in a state of rising and falling confusion concerning the meaning of that which surrounds him. The dementia disease thus means a transformation of facticity inasmuch as the hermeneutic element of facticity changes.

If facticity precedes existentiality, a transformation in the former must have a direct consequence in the latter. And this is precisely what we find: The alteration of facticity leads directly to consequences in the existential, in the normative, in the self-determining practice.

The proportion of existentiality and facticity is no longer dynamic, but rather, as we shall call it: volatile (Fig. 5).

The familiar methods for answering existential questions become inaccessible. The drama of human 


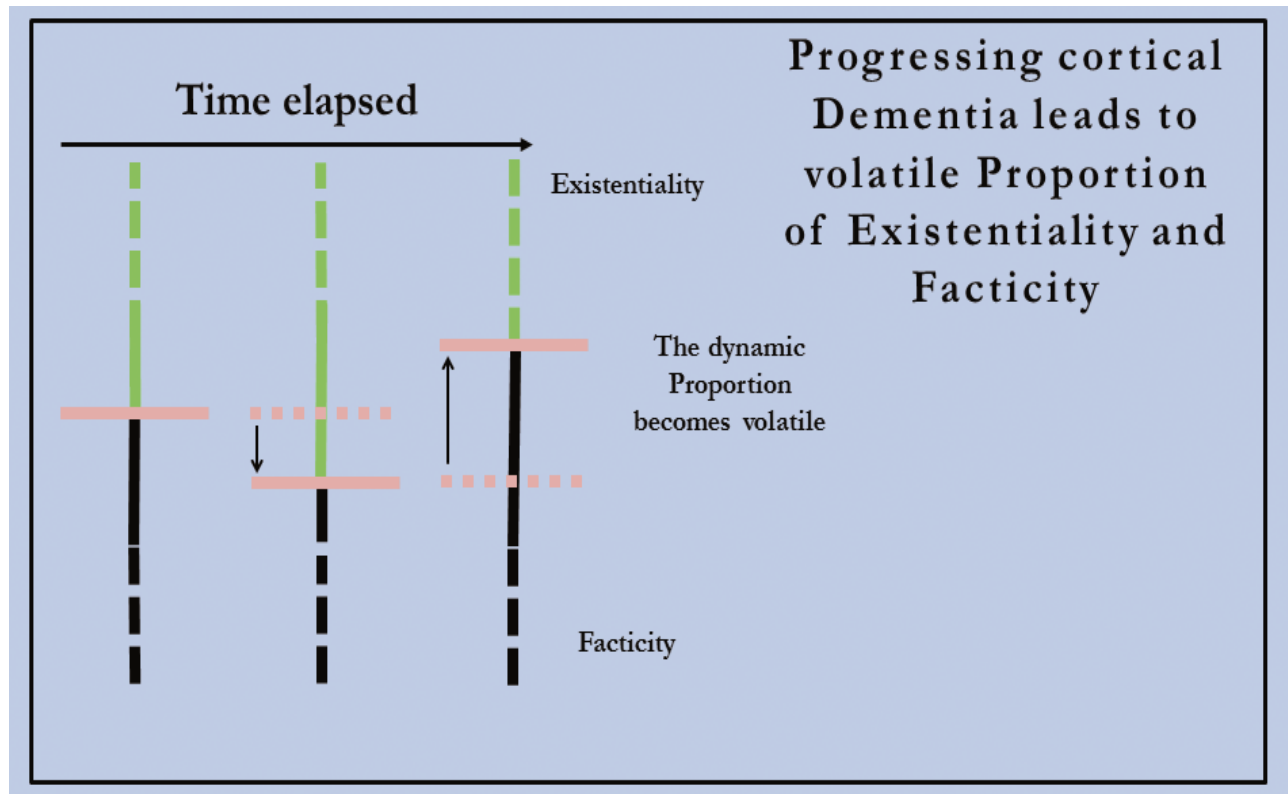

Fig. 5 Volatile Proportion of Existentiality and Facticity.

existence, coming to terms with one's own incompleteness, thus repeats itself within a person with dementia.

Mr M., as was his task throughout his life, wishes to make the rounds on the ward with his (supposed) colleagues. In the reality which surrounds him, $\mathrm{Mr} \mathrm{M}$. finds, with an assertiveness that he does not even think to question, something familiar to him: the hospital. He was able to remember his medical career very precisely, as could be recognised repeatedly from his manner and specialist knowledge, and seemingly as a matter of course, he deduced from his long-term memory and from this one comprehensible finding what was to be done.

But the meaning of this finding diminishes. In the course of his time in the hospital, the experiences of the incompatibility of this reality become more frequent, and he is no longer able to be determined within it. $\mathrm{Mr}$ M. becomes increasingly agitated. Now-and we cannot know whether there is a causal connection here or some other kind of connection-another memory begins to dominate: the thought of his wife. Here, too, we must admit that we cannot know whether this agitation and the desire to "see to things at home" perhaps has something to do with a blurred memory of the fate of his wife. But we recognise that Mr M., whatever he may tacitly remember or suspect, is indeed unclear about his wife's situation, and we hear of the considerable agitation which results from this lack of clarity. $\mathrm{Mr} \mathrm{M}$. does not know what is happening, but he wants to know. He wants to know how his wife is, he wants clarity.

Mr M. did have this clarity as to the condition of his wife at one point. He has forgotten her fate; this, too, is not unusual for an event that occurred five years previously in this stage of Alzheimer dementia. Mr M. wants to speak to his wife, he wants to know immediately if everything is alright, he wants-concerned for his wife, perhaps even: as one who loves - to engage in existential practice. $\mathrm{Mr} \mathrm{M}$. is someone who wants to know how his wife is; he has formed, as we can admittedly only suspect, a normative connection with this woman: he wants her to be well. She ought to be well. Mr M. feels, it seems, that he ought even now to remain true to this existential positing. He behaves like a person who has formed a normative connection to another and has dedicated himself practically to the ought which that entails. Seen from this perspective, he cannot be distinguished from someone who does not have 
dementia. The existential behaviour of $\mathrm{Mr} \mathrm{M}$. makes immediate sense to us. However, and this is where the difference begins, this existential behaviour is based on an assumption, for $\mathrm{Mr} \mathrm{M}$. not to be doubted, that his wife is still alive. We now find a different situation. Mr M's existential spectrum has in fact been extended, so to speak. Something that is already a reality is, in his perception, only a possibility, and his existential practice is now directed towards this, i.e. the death of his wife, which was once a reality for him, as if it were merely a possibility (Fig. 6).

The concern for his wife indeed shows that Mr M. is certain of her death as a possibility, but it also shows that he is not certain of it as a reality. This is all confirmed in the moment in which the death of his wife is communicated to him. He is shocked, he is-in our sense of the word-traumatised. He collapses in silence. At no other point during his time in hospital is the world more incomprehensible to him than now.

And then, a few minutes later, the concern for his wife begins to build up once again. Mr M. falls again into a state of stress, of anxiety and concern.

When the relationship, the proportions of the existence forms existentiality and facticity becomes volatile, existentiality also becomes volatile in its own right. The narrowing of the existential spectrum is no longer effective in the accustomed manner. When this narrowing no longer functions effectively, we find ourselves without an important method of determining who we are. We understand ourselves to a significant extent through that which we determine as our existential spectrum. And this existential spectrum is of a particular nature when we devote ourselves to a beloved person — we will simply assume here that $\mathrm{Mr}$ M. loved his wife-and of a very different nature when we commemorate a beloved person. Both may certainly be understood as a loving dedication, but there is a significant difference in whether we understand ourselves as one who loves alongside another or as a lone commemorator.

Mr M. cannot consistently focus on one practice. He is in a state of deep existential agitation, or, after the news of his wife's death, of existential shock. We thus have a man before us who wishes to engage in existential practice, but is uncertain, unstable, volatile in this practice (Fig. 7), because the ontological element of his reality hermeneutics has become overvalued.

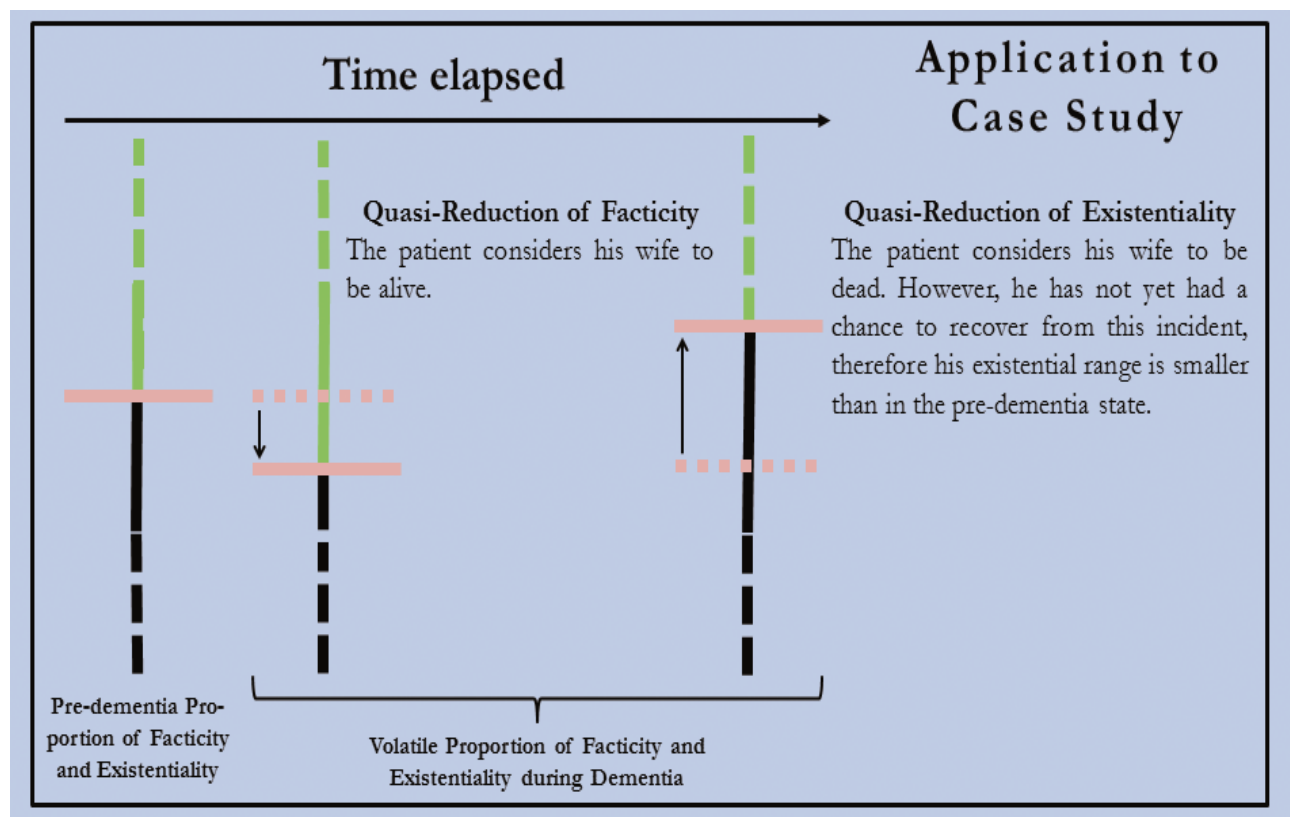

Fig. 6 Application of the model of volatile proportion of existentiality and facticity to the case study. 


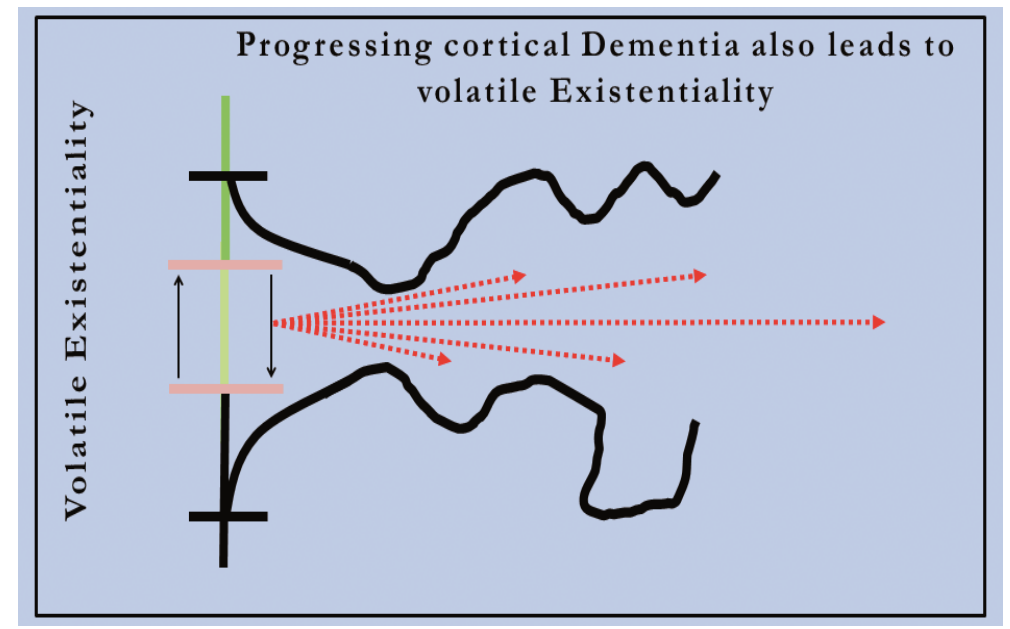

Fig. 7 Volatile Existentiality.

If the human drama does indeed (among other things) mean defying the notorious incompleteness of life and wresting, despite everything, a somewhat stable self from this incompleteness, then it is precisely this drama that is being repeated for $\mathrm{Mr} \mathrm{M}$. The tragedy of this repetition is that he can only make limited use, if indeed any use at all, of his previously successful biographical strategies.

With the memory of a previous life, at least in the pre-terminal phase of the illness, $\mathrm{Mr} \mathrm{M}$. must determine himself anew, but without the means which he possessed in that previous life. We do not know whether such a determination is even possible, and if it is possible, whether somebody else can understand it, whether it can be interpersonally communicated at all.

But one thing is certain: A cortical dementia sends anybody who experiences it into a deep existential crisis. One loses one's biography through the loss of memory on the one hand, and on the other hand, which seems to us to be of even greater significance, one loses the ability, at least as far as we can tell, to develop a new life story. The method of dealing with our practical interest in being one who is determined, namely the construction of a life story, is no longer available to someone with dementia. The interest itself, however, remains. A person with dementia is and remains in dire need of self-determination, in dire need of existentiality.

\section{Conclusions}

We consider our findings to be important for the care of people with dementia.

A person with dementia should and must be recognised as a person in an existential situation, and should be encouraged and strengthened in this situation in terms of our own particular possibilities, which differ from those of someone without dementia. Using this thought, it is possible to establish the dignity of the person with dementia theoretically, in order to demand it subsequently in practical terms.

We consider the widespread discussion of this thought to be of great significance for the furtherance of social acceptance and knowledge surrounding dementia. Due to the wide range of dementia illnesses currently evident, this idea will be of central importance in the immediate future. Dementia will be a part of society, and talk has rightly been of a 'new human mode of existence', which we must acknowledge and approach in such a way that future generations will treat people with dementia as human beings in the midst of a deep and ongoing existential struggle [11].

\section{References}

[1] Kitwood, T. 1997. Dementia reconsidered. Buckinham: Open University Press.

[2] Feil, N. 1989. Validation-The Feil Method. How to help the Disoriented Old-Old. Cleveland: Edward Feil 


\section{Repeated in the Drama of Dementia}

Productions.

[3] Kant, I. 1922. Critique of Pure Reason. Translated by Müller, F. M. London: MacMillan \& Co., Ltd., xvii [= A VIII].

[4] Kant, I. 1922. Critique of Pure Reason. Translated by Müller, F. M. London: MacMillan \& Co., Ltd., xvii [= A VIII].

[5] Freter, B. 2016 [Forthcoming]. Wirklichkeit und existentiale Praxis. Vorarbeiten zu einer Phänomenologie der Normativität entwickelt an narrativen Texten der altgriechischen, neutestamentlichen, mittelhochdeutschen und klassischen deutschen Literatur. Berlin: Lit-Verlag.

[6] Freter, B. Forthcoming. Nursing as Accommodated Care. A Contribution to the Phenomenology of Care. Appeal-Concern-Volition-Practice.
[7] Freter, B. Forthcoming. Towards a description of love: Two-fold positing and decontingentisation. A contribution to a phenomenology of normativity.

[8] This case was reported to us (entirely anonymously) by Dinah Laubisch (Department of Neurology at the Schlosspark-Klinik, Berlin). For this I would like to thank her very much.

[9] Blankenburg, W. 2012. Der Verlust der natürlichen Selbstverständlichkeit. Ein Beitrag zur Psychopathologie symptomarmer Schizophrenien. Berlin: Parodos.

[10] Wallesch, C.-W., and Förstl, H. 2012. Demenzen. Stuttgart, New York: Georg Thieme.

[11] Dörner, K. 2005. "Die neue menschliche Seinsweise der Demenz.” Bundesgesundheitsblatt-Gesundheitsforschung -Gesundheitsschutz 48 (May): 604-6. 